\title{
CHILDREN WITH DYSLEXIA: CAN THEY BE INCLUDED IN MAINSTREAM CONTEXTS?
}

\author{
Konstantina Spyropoulou \\ MA, Med, University of Nottingham, \\ United Kingdom \\ Special Education Teacher, \\ Ministry of Education and Religious Affairs,
}

Greece

\begin{abstract}
:
This paper focuses on the ongoing debate of the appropriate type of provision in mainstream or special schools and considers inclusion as the key to the education of dyslexic children (DC). Polarised views for and against mainstream and special schools have been extensively discussed by teachers, parents and students. Based on the contrasting perceptions, there is a need to investigate the implications that arise and encourage the implementation of good practice of inclusive education that should be adopted by school contexts, if certain aspects, such as teachers' attitudes, availability of the right resources and social acceptance of dyslexics' peers, are modified.
\end{abstract}

Keywords: dyslexia, inclusion, types of provision, teachers' attitudes, parents' perspectives, students' views

\section{Introduction}

During the last decades, dyslexia made researchers, teachers and parents concerned about the appropriate type of provision that children should receive. Dyslexia is characterized by Stampoltzis and Polychronopoulou (2008) as an infirmity that affects the process of reading and writing. Therefore, there is a growing debate on whether DC should become educated in mainstream or special schools and it sits within the wider context of inclusion for students with learning difficulties (LD) (Bell, McPhillips and Doveston, 2011). In other words, we talk for an inclusion debate (Kavale and Forness, 2000). Simply put, inclusion, as Avramidis, Bayliss and Burden (2000) state, is to include all children regardless of their disabilities by focusing on the accommodation rather than assimilation. DC even if they learn differently, they are not less intelligent or less capable

i Correspondence: email konstantinapaidagogos@gmail.com, spyropoulou.k93@gmail.com 
and deserve the opportunity to succeed in education (Stampoltzis and Polychronopoulou, 2008).

To show responsibility for the synthesis of this assignment, I must be aware, as a researcher of the ethical considerations. Based on BERA ethical guidelines (2011), educational research should be conducted with respect towards students-and especially vulnerable ones, teachers and parents. I will act with respectfulness and I will keep confidentiality and anonymity by not referring to participants' real names. Instead of that, I will use the initial letter of their names or name them as student 1 , teacher 2 , parent 3 and so on.

The main reason that instigated me to explore the issue of dyslexia was my experience with my cousin M. who was diagnosed with dyslexia at the age of 12 . Due to the lack of special schools in Greece, during that time, M. went to a special-private centre where a special education teacher and a speech therapist were teaching her individually. In a short time, M. became introvert, lost all of her friends, had no energy to study, and felt inferior in comparison to other children at her age. When she convinced her parents to go back to the mainstream school, all her previous friends mocked her and teachers did not pay attention to her. They thought she could not finish school. Nevertheless, her determination and willingness made her achieve her entrance to higher education, graduate, and find a job, proving to everyone that DC have nothing to be jealous of towards "normal" ones and the only difference is that they learn differently.

The following research explores different key issues relating to the suitable type of school provision for DC, from teachers', parents' and students' perspectives. Mainstream teachers, on the one hand, are not yet adequately informed and trained about dyslexia and inclusive teaching strategies and as a result, many students and parents support that special schools are a happier environment. On the other hand, special teachers are reported more qualified and children felt accepted by their peers. Negative attitudes from both peers and teachers can have an impact on a dyslexic child's selfesteem. However, regardless of the provision in different contexts, to my mind, the only thing that matters is the accomplishment of inclusion for all DC in a friendly school environment. After that, implications will be discussed, proposals for future changes will be highlighted and the need for deeper research will be also mentioned.

\section{Literature review}

The method that has been used for my research was the literature review. Critical literature review is about implementing and deepen personal and public knowledge from a field of study by showing highly capacity in reviewing, synthesizing and analysing the research of the literature (Bothell, 2015).

According to the investigation on whether DC can be included in mainstream contexts, there has been a huge controversy between mainstream and special provision. The research was based on keywords such as dyslexia, debate on school provision, inclusive education and special schools. A small number of books have been used in comparison to the variety of articles and journals. The assistance of engines such as NU 
Search, ERIC, Google Scholar and Wiley Online Library led me to articles and journals related to dyslexia and the appropriate type of provision expressed by researchers, teachers, parents and children. These articles dated mainly between 2005 and 2015. The main sources of my references were the journal of Research in Special Educational Needs, the International Journal of Inclusive Education, the International Journal of Disability, Development and Education, the European Journal of Special Needs Education, the Australian Journal of Learning Difficulties and the Scandinavian Journal of Educational Research. From this research, both quantitative and qualitative studies were examined to probe into the broadly debated educational provision for DC from all over the world within the last decade.

\subsection{Types of school provision on children with dyslexia}

As Reid (2009) states, dyslexia is usually characterized by difficulties in literacy and acquisition by affecting the way that children read, write and spell. It can also be identified as an impact on cognitive procedures and it can develop visual and/or phonological difficulties and sometimes divergences in educational performances. There are different levels of dyslexia: mild or moderate and severe. The problem lies in people who have mild dyslexia because this might cause confusion or remain unnoticed and consequently lead to a late or no diagnosis (Hultquist, 2006).

The ongoing political and scientific debate concerning which kind of provision is adequate and how it should be implemented constitutes an issue that remains unsolved (Buttner and Hasselhorn, 2011). It is already the case that articles and books have covered controversies regarding the inclusion of DC.

According to the literature, there are two main types of schools: the mainstream or ordinary-state schools and schools that specialise in dyslexia and are mostly private. Within mainstreams, children with special needs such as dyslexia can still be included. There are also some special units-resources, attached to mainstreams. One kind of school which functions as mainstream is the dyslexia-friendly school. These schools recognise the significance of social, emotional and intellectual intelligence and focus on students' strengths, something that develops confidence and self-esteem and instigates them to become more competent (McLean and Price, 2011).

On the other hand, there are special schools and some dyslexic units attached to them. International school setting is another type of school in which children are culturally and linguistically diverse, but still have similar needs (Gabor, 2010).

\subsubsection{The road to inclusion in a school context}

Inclusion constitutes a "contested discourse" (p.84) and this perception can be interpreted by different understandings in dissimilar ways that can lead to disparate practices (Wilde and Avramidis, 2011). According to Pijl (2007), inclusion is considered to be a process where systematic barriers to learning and participation are eliminated as much as possible. Successful inclusive classrooms are in need of committed and responsible teachers, with positive attitudes and abilities to distribute the curriculum and feel confident to promote the sense of inclusivity in the classrooms (Berry 2010; Blecker and 
Boakes 2010 and Lancaster and Bain 2010). On the other hand, the possible absence of positive attitudes and practices can negatively impact peer stances and emotional development (Roberts and Smith 1999; Ryan 2009). In terms of curriculum, there is also a variety of views that have been discussed. Some supported the teaching in small groups as Gabor (2010), some others argued by supporting the individualised instruction (Elliott, 2005; Reid, 2011) and those who remained somewhere in the middle (Maxwell Gillott (2014).

For the inclusionists a debate was reborn. This debate lies between the majority of people who are in favour of inclusive schools, and those who are sceptical if inclusion in mainstreams is more beneficial for DC (Hornby, 2011). For that reason, despite the existence of similar policies, there are different ways of how countries all over the world approach it.

In Ireland, reading schools operate separately from mainstreams in parallel special support, whereas reading units are attached to mainstreams but help children in the same way as in reading schools. In mainstream settings, DC are educated by learning support or resource teachers in small groups (Nugent, 2007; McPhillips and Shevlin, 2009). Bulgaria and Turkey, as Davis and Deponio (2014) refer, have resource classrooms within mainstreams. However, despite the ethos of inclusion, in reality, separation and segregation still exist. On the other hand, Spain's and Romania's support to DC was implemented within mainstream schools that operated as autonomous communities.

Another country is Greece, where children with LD are included in the general education or receive part-time support in resource rooms. These rooms operate in parallel with mainstream ones and provide teaching in small groups or individually (Anastasiou and Polychronopoulou, 2009). In Cyprus, as McLean and Price (2011) mention children get the appropriate provision by a multidisciplinary team of specialists who plan and implement their curriculum within a mainstream context. Based on Nagisa's Moritoki Škof (2015) paper, DC in Japan are educated in ordinary classes and there is special support outside the class. Lastly, in Sweden, students are included in special education in small and mixed groups within the compulsory school or classes with specific LD which constitute a part of general schools (Heimdahl Mattson, Fischbein and RollPattersson, 2010).

\subsection{Supporting dyslexic practices in different types of provision - teachers' attitudes and perceptions}

McPhillips and Shevlin (2009) tried to examine the provision that teachers offer to DC in reading schools, reading units and mainstream schools in Ireland. Based on the findings, there has been a similarity in practices for both special and mainstream settings, and more specifically some of the resource teachers asked for "more specialised training and development (...)" (ibid., p.70). In the same condition were other teachers in Leite's (2012) survey, who expressed their willingness to develop their knowledge for supporting DC. In another paper, (Bell, McPhillips and Doveston, 2011) which was based on McPhillips and Shevlin's previous study, the researchers questioned specialists and mainstream teachers on how they perceive students' difficulties in primary schools in Ireland and 
England and how they assess their learning condition. The results showed that in mainstreams for both countries, the majority of teachers seemed to be insufficiently informed on planning assessments for DC, whereas teachers in special settings in Ireland had conceptualised the nature of dyslexia and consequently, the organisation of individual assessments could be easier to conduct. These findings lead to the imperative need of professional development for teachers' training and development of inclusive practices (Bell et al., 2011), an outcome that agrees with the previous studies as well. In another study, Cameron and Nunkoosing (2012) explored thirteen of the lecturers' perceptions and experiences on dyslexia and dyslexic children's support. Participants' answers are classified as positive, neutral or negative and active, passive or resistant according to the group of themes. Based on findings, participants of the positive group perceived dyslexia as a "real" (p.346) difficulty, whereas the neutral and negative had totally diverged opinions and less awareness "And it's like-there are students who aren't very good at whatever subject. We are all better at some things than others (...) it is not-whatever it is. It's not a syndrome" (Lecturer 5) (ibid., p.347). In the active group, teachers seemed to accept their liability towards dyslexics' support and be aware of their needs by encouraging them to overcome any difficulty. Conversely, in the passive and resistant group they appeared minor or no responsibility for support:

"My general view of things like student support (...) is that we aren't the experts in that we are the experts in our subject; and when it comes to complex conditions like dyslexia, we shouldn't dabble as amateurs. We should direct students towards the expert services." (Lecturer 13) (ibid., p.347).

Lastly, Casserly (2013) examined, with a four-year research project in Ireland, how different types of provision react to socio-emotional children's needs. Reading class teachers supported children's academic and behavioural targets by encouraging talents and capabilities "their self-esteem can be raised by giving them work they can achieve, so giving them a sense of achievement and where they can never fail" (ibid., p.85). Teachers were also in favor of small classes where children could communicate with peers and teachers, find the same interests and express their emotions without embarrassment. As a result, selfesteem and confidence seemed to be enhanced when children were supported by teachers.

Conflicting views by teachers who work in mainstream or special schools have been explored and yet there is not a consensus on how teachers can be trained for helping DC. The only conclusion that can be drawn is that regardless of the type of school provision, teachers must be first aware of dyslexia and train themselves appropriately for implementing the most effective methods and inclusive strategies that fit each individual.

\subsection{In favor of special or mainstream inclusive settings? - parents' perspectives affected by students' experiences}

Parents constitute the key players for helping, supporting, and encouraging DC. Based on the literature research, there is a great controversy of opinions among parents, related 
to the educational placement of dyslexics' children (Elkins, van Kraayenoord and Jobling, 2003).

"Is it a better educational experience for the child to be included in mainstream schooling or to attend a school or unit designed to address their specific needs?" (Peer and Reid, 2001, p.267), one mother wondered, as having experienced dyslexia because of her son.

Based on Rontou's case study (2010), mothers of DC in Greece stated the kind of provision they wish for their children. All mothers agreed that they prefer mainstream schools with individualised programs and special needs teachers or assistants. One mother stressed that she would be interested in sending her child to special pilot programs that operate in mainstreams. Another mother said: "we go [to a private centre] because they [diagnostic centres] don't have space and there is no coordination at all" (ibid., p.189). One more participant agreed with the previous view by supporting the notion that special classes should categorise children according to their needs and not mix them all in the same class. She was also in favor of parallel support (that does not function for DC in Greece), but she would like to, an opinion that paralleled with the view of the first mother (ibid).

Two mothers, of the case studies as Konur (2005) stated, attempt to assert equal access to compulsory education and equal educational provision appropriate for their children. The Tribunal declined about placing their children in special schools and insisted on placing them in mainstream settings, without taking into consideration the lack of adequate provision for them.

In another Australian study, diverse parents' views upon types of provision were expressed. Most of them supported inclusion due to the fact that mainstream classes offered "a great programme", "a very caring aide", "wonderful staff", "has made great progress" and "she has made friends" (Elkins et al., 2003, p.155). Only a minor number were opposed to it, by explaining that their children's severity could not be accommodated there. Few of the parents were content with the special settings and on the contrary, they were more hesitant about mainstreams, because of the poor behaviour of their peers (ibid).

In Bangkok, parents were interviewed about adequate educational provision for DC at international schools and made the following statement:

"The school looked at the individual person. It's not like you are this age and you should be doing this, it's what can we do for you." (Parent 1) (Brown and Bell, 2014, p.163).

On the other hand, some parents found the opposite on other local international schools:

“...the headmistress (...) said to me, "No we don't want him. He'll keep our numbers down" (...) We were told by two schools that he wasn't up to their standard." (Parent 2) (ibid., p.161).

"We just had an example from one school with friends of us (...) there is a kid with a syndrome and they asked the parents to take the kid out." (Parent 3) (ibid., p.161). 
In another study (Nugent, 2008) parents were asked to comment on their children's experience of special education in Ireland. Related to children's happiness at school, parents were most contented in special schools, while in the resource settings were the least. As a consequence, parents did not report that their children felt "more normal" (p.200) in resource teaching, in comparison to their agreement with this statement in special schools and reading units. By concluding, parents mentioned that children who attended special schools proved to be happier and gained more positive experiences, contrasting to resource settings (ibid). In a previous Nugent's study (2007), parents also expressed positive views regarding a special provision in all settings, and only $1 \%$ was disappointed. Parents of pupils who received special provision tended to be more satisfied than those whose children were educated in the mainstream. As Nugent (2007) says, this is mainly caused by the fact that mainstream schools did not manage to correspond to dyslexic children's needs. More specifically, as a parent mentioned, mainstreams do not inform parents for the right of their children's education, but encourage them to educate them in another place "... his former school declined to help him in any way and instructed us to remove him from the school. We were under pressure to find another school for him (...)" (ibid., p.56).

In Casserly's study (2013), parents claimed that most of the children faced adverse socio-emotional feelings in mainstreams before their training in reading school/class, something that decreased after their experience in the special settings. Parents stated that children characterized themselves as different and useless in mainstreams. Parents justified that due to their similarities with their peers they were feeling equal and accepted in special settings. Concerning their self-esteem during reading schools, seven out of fourteen said that it had raised, three that it was stable and three that it diminished, but all of them agreed that by leaving from there, it has been improved. When children returned to mainstream settings most of the parents noted their children's satisfaction and positive attitude because of their peers and learning experiences, in comparison to the first time (ibid).

To conclude, nearly one third said that they would like their children to be educated in mainstream resources rather than special. Such finding was supported by parents' personal accounts, but based on the surveys in which children receive all forms of provision, it was concluded that they were happier with special provision. The contrast between the most preferable types of provision according to parents' experiences is still an ongoing debate. However, the most vital thing that parents chase is the provision that can be proven beneficial for their children's learning development, social interaction and emotional enhancement, regardless of the place.

\subsection{Students' views about teachers' behaviour in mainstream and special schools}

McPhillips and Shevlin (2009) tried to include students' voices regarding teachers' assistance in combination with different school provisions in Ireland. Two of them quoted their contrasting views "We were doing work that was too hard for us [in the mainstream] and they didn't give us much help (...)" (ibid., p.68), "In this school (reading unit) the teacher will help you(...)" (ibid., p.69). These experiences showed that education in 
special contexts has been estimated as more beneficial, in stark contrast to the mainstream. In another study, a group of students from Sweden were interviewed for their experiences about teachers' attitudes and then for the possibilities of participating in special settings. Regarding the first aspect, one student stressed:

"They grumbled at me. They told me I was totally useless and couldn't do anything." (Heimdhal Mattson et al., 2010, p.246).

In Riddick's study (2001), thirteen years old child, also reported to their teachers that they thought he/she was an idiot and moron. On the other hand, another student described a positive experience:

"I met B that was probably what got me to where I am now (...), she found solutions (...) I can't get hold of things by reading and writing. B understood that." (Heimdahl Mattson and Roll-Pattersson, 2007, p.246).

Regarding the second aspect, students also exposed opposing views about being educated in small or individual groups "It was nice to be in a small class, to know who you were (...)The teachers knew their job (...)they were more fair." (student 1)(Heimdahl Mattson and Roll-Pattersson, 2007, p.247). Contrariwise, student 2 stated his disappointment about being in an exclusively segregated group that did not operate within the mainstream class (ibid). Lastly, students quoted their views on lecturers' attitudes on dyslexia. Based on teachers' sayings, they were characterized as prejudiced, incredulous and uncertain for the existence of dyslexia, whereas good teachers' attitudes were positively evaluated by students because of showing a willingness to help, rapport and trustworthiness (Pino and Mortari, 2014).

\subsubsection{Effects on social and emotional developments - children's' viewpoints}

One of the most crucial factors that is responsible for dyslexic students' self-esteem is the provision of proper educational contexts (Riddick, 2006).

In order to find out how different educational contexts reacted to dyslexic persons' self-esteem, the study of Nalavany, Carawan and Brown (2011) reported that school recollections were fearful in mainstreams and less stressful for those who were educated in special settings. There had actually greater levels of self-esteem because they were educated by qualified teachers and received peer support that enhanced self-esteem through positive emotional development. Another study also focused on teachers, parents and peers who affected children's self-esteem in mainstream schools (Glazzard, 2010). Several children who made a comparison between them and their peers felt isolated and disappointed, whereas half of the students expressed the opposite opinions:

"No I never experienced anything negative because of my dyslexia. It's just dyslexia (...). It doesn't change who you are. Everyone has been fine with me. I mean, I used to make fun of myself about my spelling." (Student no. 7) (ibid., p.66). 
Children's perceptions about their teachers were also contrasting. Most of the children recollected bad memories from teachers' behavior "(...) He used to make comments like say I was rubbish and that I'd never get anywhere in life (...)" (Student4) (ibid., p.65),

"(...) She used to bully me. I didn't like her (...) She used to get me in front of the class and humiliate me in front of the others. Then she'd make me sit in a corner and encourage the class to laugh at me. She was horrible (...) When it was playtime she'd always give me extra work and I'd never get a break (...). She used to call me stupid..." (Student no.8) (ibid., p.65).

Conversely, there were DC who had good experiences with their teachers and characterized them as supportive and understanding:

"Well, the person I think has done the most and really supported me is Mrs. S (...) She's always been there if I've needed someone to talk to or needed help. If I'm feeling down I'll go and talk to her and she has always sorted it out for me (...) She's the only teacher in the school that's really done wonders for me (...)" (Student no.9) (ibid., p.65).

Nugent (2008) decoded interviews from DC who were educated in three different Irish settings. Based on the results, children seemed to be happy with special provision in all three settings, and they appeared to have a more positive attitude towards special schools and reading units rather than children in mainstreams. Special provision appeared to unite students with similar difficulties, within the same group, something that raised positive contrasts. Contrariwise, self-esteem and especially academic one caused adverse impact on DC in mainstream context and especially feelings of isolation and refusal from the others. Children stated: "I wasn't good enough - I couldn't read as well as others" (ibid., p.198). The statistical percentages present that $63 \%$ of the students were in favor of continuing with a special provision, $7 \%$ of them were uncertain and $30 \%$ did not want to attend special provision in secondary school because they wanted to be "normal" (p.199).

Stampoltzis and Polychronopoulou (2009) investigated the educational experiences of university students with dyslexia during their school years. Children's school experiences from primary school were in general adverse and had a repercussion on their self-confidence. As they grew up the differences were more restricted and they learned to develop ways to cope with their inconveniences. The three groups of questions were about past school experiences, present difficulties, and future plans. Related to their primary schools' previous experiences, most of them were disappointed "My memories are bad (...) I thought myself (...) probably a failure. One thing I remember is when I was in the sixth grade, my teacher slapped me in front of the class because of my spelling errors". (G)(ibid., p.312). Some others were satisfied by the teachers' reactions and understanding towards their problems though. Children's experiences in secondary education appeared more auspicious, as they made friends and despite their difficulties, they could control things with the assistance of their teachers. As a result, they became more confident in 
themselves. Peer relationships were most effectively developed "My problem didn't affect my relations with my classmates. We had a good time together" (K) (ibid., p.313) and only a minority of students faced problems with that.

Children's self-esteem is enhanced mostly as a result of parental contribution. All students stated that they gained only good influence from their parents at schoolwork and for their self-esteem (Stampoltzis and Polychronopoulou, 2009; Glazzard, 2010):

"My parents showed great understanding and helped me a lot. Their help acted as a catalyst to my success at university" (P) (Stampoltzis and Polychronopoulou, 2009, p.314).

"Yeah both my parents are supportive (...) They encourage me to do my best." (Student no.6) (Glazzard, 2010, p.66).

According to children's future plans, there is optimism about their job careers and they are ready to set up their businesses and work with loyalty (Stampoltzis and Polychronopoulou, 2009). To sum up, children reported mostly a preference for special schools because there could feel more accepted and teachers were more specialized in their needs. However, these findings that were based on their school experiences would be much different from the current ones if children in mainstreams were given instructions by qualified teachers concerning strategies and materials (ibid).

Based on Casserly's investigation, on a four-year project (2013), children's experiences on their socio-emotional development, according to their placement in mainstream and reading class and their return to the mainstream, were discussed. Children experienced difficulties in mainstream school. They could not keep up with their peers, whereas in special classes they could deal more effectively with their work. With their relocation to the mainstream, the majority of children expressed their happiness for being again with their peers, complete and compare their work, recognize their abilities, and feel like they belong there. Additionally, one pupil supported the mainstream more than the special school and explained why:

"The things I like about the big mainstream class are that I don't have to leave the class for some lessons and I have made lots of new friends. The disadvantage of being in the reading class was that I was the only girl and I was bullied by two boys (...) who used to call me names. I feel happier in mainstream and I feel I belong." (ibid., p.87).

Overall, teachers', parents' and students' perceptions and attitudes towards the appropriate type of provision with the sole aim of dyslexic child's inclusion in the educational system constituted a debate of far-reaching importance. Both positive and negative views explored and the impact on children also discussed. Implications for future practice are going to be introduced in the next chapter. 


\section{Implications for practice}

In order to provide an appropriate school provision for dyslexic children's education, we have to find out what makes a good inclusive practice. Based on the literature, during the last decade, DC have been educated in both mainstream and special schools/classes that operate within mainstreams. However, a consensus on the appropriate school environment that would facilitate their knowledge and accommodate their individual needs does not yet exist. It is then our responsibility as educators to find out which are the factors that influence the effectiveness of inclusion. These can be found directly from the executed research by including teachers' attitudes, the curriculum and the available resources and the social acceptance of the child within the classroom. Last but not least, implications of how DC are educated in my country will be mentioned as well as recommendations of good future practice.

\subsection{Change of teachers' attitudes}

As it is apparent from the research, teachers' behaviours can influence students' selfconcept. For that reason, a change to teachers' attitudes is necessary. During the research, the findings that were mostly negative showed students' reactions that came as a result of teachers' behaviours and how these behaviours affected the perception for themselves. Adverse attitudes have long-lasting effects on students (Nielsen, 2011). For that reason, teachers' education is essential. Teachers must learn to focus on the personality of dyslexic children and cater to their needs by learning their backgrounds and understand that they need special treatment. This can be mainly achieved with the cooperation of parents and teachers. However, the biggest challenge for teachers, as the majority of authors claim, is the appropriate training (Bell et al., 2011; Nalavany et al., 2011; Cameron and Nunkoosing, 2012). This is because they need to understand and accept first the wide spectrum of difficulties and especially the learning ones and then to obtain skills that will support children in an inclusive dyslexia-friendly school environment. Another thing teachers should do is to give to DC space, time (Nielsen, 2011; Leite, 2012) and cultivate mutual rapport between them and their students, to help them overcome the barriers of their learning procedure (Pino and Mortari, 2014) and enhance their self-esteem. Most importantly, teachers must realise that all students are capable of learning, but each one of them learns differently (Leite, 2012). Cameron and Nunkoosing (2012) offer a solution, which outlines that current or past dyslexic students can design a training program for their teachers according to their experiences, in order to find out what kind of support suits them better. Finally, children are those who need teachers' support, attention and encouragement, in order to be able to handle their adversities in their way, no matter how hard they are about to try (Nielsen, 2011).

\subsection{The curriculum and school resources in the classroom}

The appropriate curriculum for DC must be flexible and easily adaptable to their individual needs. This sets in the centre each dyslexic child and promotes equality and 
respect (Leite, 2012). Teachers constitute the mediators of the curriculum's design and of the provided knowledge that should be adapted to children's needs.

In order to ameliorate curriculum access in the classrooms and implement a good quality of teaching, teachers need the appropriate resources (Coffield and O'Neill, 2004). Some of the possible support materials could be multi-sensory or technological tools and books with an interesting and comprehensible context that could teach them the ways of improving their literacy skills and develop their linguistic level (Nielsen, 2011). These resources can go along with the designed curriculum. For example, the curriculum might include behavioural activities such as role-plays, small exercises with specific instructions from the teachers and discussions for the possible solutions with their peers in small groups. If teachers implement all these resources and teaching strategies then will give them the chance to set targets, show their abilities (Firth, Frydenberg, Steeg and Bond, 2013), participate successfully as full members of the classroom, and defy some of the serious barriers that may arise because of their LD (Bell et al., 2011). Finally, teachers can create a safe and structured environment where DC will feel that they belong and lead happier school lives (Firth et al., 2013).

\subsection{Social acceptance within the school context}

Another area that plays a major role in dyslexic children's inclusion is to become socially accepted by their peers in the classroom. As research implied, negative attitudes from their peers, made them feel isolated, excluded and with low self-concept. As Nalavany et al., (2011) mentioned children who were educated in special settings received more support from their peers, something that is in stark contrast with mainstreams, where dyslexics faced social and emotional seclusion. More specifically, as shown in previous studies of the literature, students asserted that they would be benefited from interaction with other dyslexic peers because they had common difficulties and consequently similar needs. As aforementioned in the previous section, if students take part in collective activities, they will formulate good working relationships with their peers and as a result will gain their interest, appreciation and respect. The negative attitudes towards DC are mainly formed by stereotypes and prejudices of the society that tend to consider them as "rubbish", useless and unable to be educated with "normal" children. These beliefs are created by the lack of information and education and are passed from parents to their children. As a result, in order to reach social acceptance, we should first raise awareness of the problems that people with special educational needs face, especially within the school communities, and sensitise them about equality and human rights. In this way, parents will transmit these ethical values to their children. Finally, the social acceptance of DC can bring life-changing effects on their future educational and socio-emotional developments and influence positively their future paths in life.

All three aspects that are mentioned above are interrelated with each other and if they operate effectively, they can contribute to the enhancement of self-esteem and the improvement of children's emotional condition. These positive effects lead to the amelioration of learning, better interaction with their peers and collaboration with their teachers. To conclude, schools, no matter if they are mainstream or special, are trying to 
adopt an inclusive ethos, something that is prevented by a lack of professional expertise, suitable resources, and the peer community that cannot still accept and integrate dyslexic children in mainstream schools. Given the appropriate policies of inclusive education, DC will be able to become literate in tandem with their non-dyslexic peers in a mainstream school context (Elkins et al, 2003).

\subsection{Back home situation}

According to my back-home situation, in Greece, DC get a diagnosis by KESY (Educational and Counseling Support Center). This diagnosis includes the child's examination by a team of special education staff who confirms his/her condition and indicate his/her education in resource rooms or otherwise integration classes, within the mainstreams, individually or in small groups with other dyslexic peers. There is not yet legislation on parallel support, which follows inclusive education policies, for them to become educated in the same class with their non-dyslexic peers. Consequently, DC most times feel isolated and excluded from the learning process with less interaction and communication with others and fewer possibilities to improve their self-esteem, to become confident, and believe in their abilities. For that reason, my recommendation consists of a good policy that could enact the legislation of parallel support for DC, to allow them to feel important and become literate in a fully inclusive environment, surrounded by supportive teachers with inclusive strategies, who will eliminate their weaknesses and promote their strengths.

Nevertheless, instead of debating the appropriate type of provision, the research focus should consequently be placed on the effectiveness of the inclusive support given to every child in the school environment. The following research question could hopefully make an impact on further research for future investigations, in order to explore the feasibility and effectiveness of an inclusive school environment applied to children's needs: Is inclusive teaching at risk of becoming "silent" segregation? (Heimdahl Mattson and Roll-Pattersson, 2007, p.250). If this question sets the starting point for our future research, many more are about to follow.

In my opinion, the cooperation between special and mainstream schools increases the likelihood of developing inclusive strategies within educational systems and by working together benefits are presented to all members of the school community. The most vital expectation that matters for children to feel included is the creation of an environment that provides them with suitable academic, social and emotional experiences that can ultimately boost children's self-esteem (Nalavany et al., 2011). From the research on the literature, some future questions arise. Is there an appropriate way to deliver special education placement's profits to children in inclusive settings? Or if the education in mainstreams causes problems for some students, then what makes the attendance in a special school more beneficial? The starting point should be the mainstream context and its inclusiveness or the needs of specific groups with particular interests?

Further research is needed in order to investigate possible answers to the aforementioned questions. 


\section{Conclusion}

Whether DC should be included in mainstream or special contexts is a widely debated topic that is discussed from the point of teachers', parents' and students' views. There was never a unanimous view on whether mainstream provision is more beneficial than special. This paper examined how countries all over the world perceive inclusion for children with LD. How these children experienced teachers' and peers' attitudes and what impact they had on them. The major contradictory fact concerns teachers' training to cater to children's needs and their positive attitudes, in order to promote healthy academic, social and emotional developments within the school environment.

According to the findings of the literature, there are several parents (Peer and Reid, 2001) and students (Nugent, 2008) that are engaging for more specialist provision, as they feel happier than in mainstreams. That surely does not mean that parents reject the concept of inclusion, but they do not want their children to become educated in a place that does not offer the appropriate support based on their specific LD (Peer and Reid, 2001).

To conclude, the concept of inclusion has not yet been fully defined and is likely to continue evolving. The focus should be on further improvements in teachers' attitudes, the curriculum and school resources and the acceptance of their peers. However, as a teacher that adopts inclusive beliefs, there is still more research needed not about the type, but towards the quality and effectiveness of school provision for DC.

\section{Conflicts of interest}

The author declares that there are no conflicts of interest.

\section{Acknowledgements}

I would like to devote this space in order to thank the people who have contributed towards the completion of this assignment.

First of all, I would like to express my gratitude to all the professors of the MA Special Needs course (University of Nottingham) who inspired me as an educator and enlightened me to become a good researcher.

Also, I would like to express my very great appreciation to my beloved parents and sister for their valuable financial and emotional support. Especially, I would like to thank my mother, whose endless love and patience were encouraging and supporting me to pursue my goals during this year.

Finally, I would like to thank my friends who believed in me and made this journey worthwhile during my studies at the University of Nottingham.

\section{About the Author}

Konstantina Spyropoulou was born in Volos (Greece). She studied at the Faculty of Preschool Education at the University of Thessaly where she received her Bachelor's Degree in 2015. She did postgraduate studies in the United Kingdom, where she got her Master of Arts Degree in the field of Special Education (2016) and she also got a Master 
in Education in the field of Intercultural Education (2018). Moreover, Konstantina is an undergraduate student at the National and Kapodistrian University of Athens in the sector of French Language and Literature. She obtains a qualified teacher status (QTS) in order to teach in a maintained school or non-maintained special school in England. She has worked voluntarily as a teacher/teaching assistant in the United Kingdom both in Special and Mainstream schools. In addition, she has been working in Greek public schools, as a Special Education Teacher, at the Ministry of Education since 2017, by supporting students with Special Educational Needs and behavioral problems with oneto-one teaching or/and group sessions. Moreover, Konstantina has been providing professional teaching support since 2015 to children with or without special needs as well as bilinguals, aged from 4 to 12 years old. She fluently speaks Greek, English and French. She possesses Braille certification and she knows the Greek Sign Language. She has participated in many seminars, conferences and educational programs. She has also gained many certificates of specialization in relevant educational sectors. Her research interests focus on the following: Teaching Methods in Preschool and Primary Education, Interventions in Special Education, Behavioral Management of students with autism, ADHD, psychological and social difficulties as well as Adaptation of bilingual students.

\section{References}

\section{a. Books}

Hultqust, A. M. (2006). An Introduction to Dyslexia for Parents and Professionals. Jessica Kingsley Publishers.

McLean, B. and Price, G. (Eds.) (2011). The Dyslexia Handbook. British Dyslexia Association.

Peer, L. and Reid, G. (2001). Dyslexia-successful inclusion in the secondary school. London: D. Fulton Publishers.

Reid, G. (2009). $4^{\text {th }}$ ed. Dyslexia: a practiotioner's handbook. John Wiley \& Sons Publishers.

Reid, G. (2011). $3^{\text {rd }}$ ed. Dyslexia. London: Continuum International Publishing Group.

\section{b. Journal Articles}

Anastasiou, D., and Poychronopoulou, S. (2009). Identification and Overidentification of Specific Learning Disabilities (Dyslexia) in Greece. Learning Disability Quarterly, 32(2), pp.55-69.

Avramidis, E., Bayliss, P., \& Burden, R. (2000). Student teachers' attitudes towards the inclusion of children with special educational needs in the ordinary school. Teaching and Teacher Education 16, pp.277-293.

Bell, S., McPhillips, T. and Doveston, M. (2011). How do teachers in Ireland and England conceptualise dyslexia?. Journal of Research in Reading 34(2), pp.171-192.

Berry, R. A. W. (2010). Preservice and early career teachers' attitudes toward inclusion, instructional accommodations, and fairness: Three profiles. The Teacher Educator 45(2), pp.75-95. 
Blecker, N. S., and Boakes N. J. (2010). Creating a learning environment for all children: Are teachers able and willing?. International Journal of Inclusive Education 14(5), 435447.

Brown, J. and Bell, S. (2014). Supporting young people with dyslexia in international schools: a case study example of current provision in Southeast Asia. Support for Learning, 29(2), pp.154-166.

Büttner, G. and Hasselhorn, M. (2011) Learning Disabilities: Debates on definitions, causes, subtypes, and responses. International Journal of Disability, Development and Education 58(1), 75-87.

Cameron, H. and Nunkoosing, Dr. K. (2012). Lecturer perspectives on dyslexia and dyslexic students within one faculty at one university in England. Teaching in Higher Education, 17(3), pp.341-352.

Casserly, M. (2013). The socio-emotional needs of children with dyslexia in different educational settings in Ireland. Journal of Research in Special Educational Needs, 13(1), pp.79-91.

Coffield, M. and O'Neill, J. (2004). The Durham experience: promoting dyslexia and dyspraxia friendly schools. Dyslexia, 10(3), pp.253-264.

Davis, J. M. and Deponio, P. (2014). Analysing conflicting approaches to dyslexia on a European project: moving to a more strategic, participatory, strength-based and integrated approach. International Journal of Inclusive Education, 18(5), pp.515-534.

Elkins, J., van Kraayenoord, C. and Jobling, A. (2003). Parents' attitudes to inclusion of their children with special needs. Journal of Research in Special Educational Needs, 3(2), pp.122-129.

Elliott, J. G. (2005). Dyslexia: Diagnoses, Debates and Diatribes. Education Canada, 46(2), pp.14-17.

Firth, N., Frydenberg, E., Steeg, C. and Bond, L. (2013). Coping Successfully with Dyslexia: An Initial Study of an Inclusive School-Based Resilience Programme. Dyslexia, 19(2), pp.113-130.

Gabor, G. (2010). Can students with dyslexia be effectively supported in the diversity of an international school setting? Journal of Research in Special Educational Needs, 10(1), pp.31-41.

Glazzard, J. (2010) The impact of dyslexia on pupils' self-esteem. Support for Learning, 25(2), 63-69.

Heimdahl Mattson, E. and Roll-Pettersson, L. (2007). Segregated Groups or Inclusive Education? An Interview Study with Students Experiencing Failure in Reading and Writing. Scandinavian Journal of Educational Research, 51(3), pp.239-252.

Heimdahl Mattson, E., Fischbein, S., and Roll-Pettersson, L. (2010). Students with reading difficulties/dyslexia: a longitudinal Swedish example. International Journal of Inclusive Education, 14(8), pp.813-827.

Hornby, G. (2011). Inclusive education for children with special educational needs: a critique. International Journal of Disability, Development and Education, 58(3), pp.321329. 
Kavale, K. A. and Forness, S. R. (2000). History, rhetoric, and reality: analysis of the inclusion debate. Remedial and Special Education 21, 279-296.

Konur, O. (2006). Participation of children with dyslexia in compulsory education: current public policy issues. Dyslexia, 12(1), pp.51-67.

Lancaster, J., and Bain, A. (2010). The design of preservice inclusive education courses and their effects on self-efficacy: A comparative study. Asia-Pacific Journal of Teacher Education, 38(2), pp.117-128.

Leite, S. (2012). Dyslexia through the eyes of primary school teachers. Procedia-Social and Behavioral Sciences, 69, pp.41-46.

McPhillips, T. and Shevlin, M. (2009). Evaluating the teaching and learning experience for the child with dyslexia in special and mainstream settings in Ireland. Support for Learning, 2(2), pp.63-72.

Moritoki Škof, N. (2015). Japanese language education and dyslexia: on the necessity of the dyslexia research. Acta Linguistica Asiatica, 5(1), pp.71-83.

Nalavany, B., Carawan, L. and Brown, L. (2011). Considering the role of traditional and specialist schools: do school experiences impact the emotional well-being and selfesteem of adults with dyslexia? British Journal of Special Education, 38(4), pp.191200.

Nielsen, C. (2011). The Most Important Thing: Students with Reading and Writing Difficulties Talk About their Experiences of Teachers' Treatment and Guidance. Scandinavian Journal of Educational Research, 55(5), pp.551-565.

Nugent, M. (2007). Comparing inclusive and segregated settings for children with dyslexia: parental perspectives from Ireland. Support for Learning, 22(2), pp.52-59.

Nugent, M. (2008). Services for children with dyslexia - the child's experience. Educational Psychology in Practice, 24(3), pp.189-206.

Pijl, S. J. (2007). Introduction: the social position of pupils with special needs in regular education. European Journal of Special Needs Education, 22(1), pp.1-5.

Pino, M. and Mortari, L. (2014). The Inclusion of Students with Dyslexia in Higher Education: A Systematic Review Using Narrative Synthesis. Dyslexia, 20(4), 346369.

Riddick, B. (2001). Dyslexia and inclusion: Time for a social model of disability perspective?. International Studies in Sociology of Education, 11(3), pp.223-236.

Riddick, B. (2006). Dyslexia friendly schools in the UK. Topics in Language Disorders, 26 (2), pp.144-156.

Roberts, C. M., and Smith, P. R. (1999). Attitudes and behaviour of children toward peers with disabilities. International Journal of Disability, Development and Education, 46(1), pp.35-50.

Ryan, T. G. (2009). Inclusive attitudes: A preservice analysis. Journal of Research in Special Education Needs, 9(3), pp.180-187.

Stampoltzis, A. and Polychronopoulou, S. (2008). Dyslexia in Greek higher education: a study of incidence, policy and provision. Journal of Research in Special Educational Needs, 8(1), pp.37-46. 
Stampoltzis, A. and Polychronopoulou, S. (2009). Greek university students with dyslexia: an interview study. European Journal of Special Needs Education, 24(3), pp.307-321.

Wilde, A. and Avramidis, E. (2011). Mixed feelings: towards a continuum of inclusive pedagogies. Education 3-13, 39(1), pp.83-101.

\section{c. Online Sources}

British Educational Research Association (BERA) (2011). Ethical Guidelines for Educational Research. Available at: https:/www.bera.ac.uk/wpcontent/uploads/2014/02/BERA-Ethical-Guidelines-2011.pdf?noredirect=1 [Accessed 10 November 2015].

Maxwell Gillott (2014). SEN: Dyslexia [online] Available at: http://www.maxwellgillott.com/services/education/dyslexia-special-educationalneeds.aspx [Accessed 11 January 2016].

Rontou, M. (2010) Provision for students with dyslexia in EFL: an ethnographic case study [online]. PhD Thesis, University of Birmingham. Available at: http://etheses.bham.ac.uk/1237/1/Rontou10EdD.pdf [Accessed 15 December 2015].

University of Washington/Bothell (2015). Critical literature review [online] Available at: https://www.uwb.edu/med/medstudenthandbook/acadprogramrequirements/lit review [Accessed 11 December 2015]. 
Creative Commons licensing terms

Authors will retain the copyright of their published articles agreeing that a Creative Commons Attribution 4.0 International License (CC BY 4.0) terms will be applied to their work. Under the terms of this license, no permission is required from the author(s) or publisher for members of the community to copy, distribute, transmit or adapt the article content, providing a proper, prominent and unambiguous attribution to the authors in a manner that makes clear that the materials are being reused under permission of a Creative Commons License. Views, opinions and conclusions expressed in this research article are views, opinions and conclusions of the author(s). Open Access Publishing Group and European Journal of Special Education Research shall not be responsible or answerable for any loss, damage or liability caused in relation to/arising out of conflict of interests, copyright violations and inappropriate or inaccurate use of any kind content related or integrated on the research work. All the published works are meeting the Open Access Publishing requirements and can be freely accessed, shared, modified, distributed and used in educational, commercial and non-commercial purposes under a Creative Commons Attribution 4.0 International License (CC BY 4.0). 